\title{
De sopranos e barítonos ou como Eça de Queirós revisita a ópera do século XIX
}

\author{
Jorge Valentim \\ (Universidade Federal de São Carlos)
}

\section{RESUMO}

O presente ensaio tem como objetivo propor uma leitura do romance de Eça de Queirós, O primo Bazílio, a partir das referências diretas às operas e peças musicais mencionadas e performatizadas ao longo da narrativa. Tais citações funcionam como intertextos musicais, no sentido de propiciar um diálogo entre os discursos musicais instrumentais e vocais com a trama ficcional, incidindo de maneira significativa na construção da trajetória dos personagens. Conhecedor das técnicas de composição operística em vigor na Europa e leitor das condições sociais do seu país, Eça de Queirós parece revestir suas criaturas de timbres vocais específicos, dando-lhes assim uma função representativa e colocando em prática o seu projeto de olhar irônico sobre o idealismo romântico.

PALAVRAS-CHAVE: Ópera, Realismo, Diálogo Intertextual

\section{ABSTRACT}

This essay aims to propose a reading of Eça de Queirós' novel, O primo Bazillio, starting from its direct references to the mentioned performed operas and musical pieces along the novel. These references serve as musical intertexts in order to facilitate a dialogue between the instrumental and vocal musical discourses with the fictional plot, incurring in a significant manner in the characters' trajectory. Knowing the techniques of operatic composition in force in Europe and reader of the social conditions of his country, Eça de Queirós seems to take their creatures of specific vocal tones, giving them a representative function and putting into practice his design of a ironic looking about romantic idealism.

KEYWORDS: Opera, Realism, Intertextual Dialogue 
Assim a Música aparece neste século como uma voz inesperada em que se entendem os desconsolados. $E$ os desconsolados foram toda uma mocidade triste e enervada, toda uma primavera sagrada.

Eça de Queirós. Correspondência de Fradique Mendes.

Dentro dos estudos culturais direcionados ao século XIX, é já um consenso das críticas literária e musical que o período oitocentista europeu é marcado pelo amadurecimento e apogeu de dois dos principais gêneros da época. De um lado, o romance que, na esteira da ideologia burguesa, se tornou o meio de divulgação e propagação dos mais variados pontos de vista sobre o domínio burguês na literatura e nas artes. De outro, a ópera que, favorecida pelas construções dos grandes teatros, pela difusão febril da escola italiana do bel canto, bem como pelas suas companhias teatrais, e pela criação e produção de determinados enredos dramáticos, soube colocar no palco, não apenas as circunstâncias ficcionais do Oitocentos, mas também atendeu ao gosto de um determinado público com uma realização musical compreensível, na abrangência das suas três principais escolas: a italiana, a francesa e a alemã. $^{1}$

Como na Península Ibérica, sobretudo em Portugal, não se chega a formar uma escola operística propriamente dita - sem menosprezar, é claro, os casos de Ciríaco Cardoso, Arthur Napoleão e Francisco Sá de Noronha, dentre outros -, é compreensível o fato de muitas companhias de ópera terem invadido os palcos portugueses com as obras de compositores italianos, franceses e alemães, ditando assim um gosto público que tentava colocar Portugal ${ }^{2}$ na rota dos principais centros culturais e intelectuais da Europa.

Neste sentido, observador arguto da cidade e da sociedade de Lisboa, Eça de Queirós constrói em O Primo Bazíliỏ, para além de um "episódio doméstico" e de uma das mais reconhecidas obras do Realismo português, uma espécie mesmo de drama operístico, onde não faltam as figuras da prima donna, do amante sedutor, do marido traído, do amigo incondicional, da vilã aterrorizante e de personagens giocosos. É bom lembrar, aqui, que tal técnica de composição não era de todo desconhecida do escritor português. Em "Antero de Quental", de 1896, o próprio Eça confessa que "Sob a influência de Antero logo dois de nós, que andávamos a compor uma ópera bufa, contendo um novo sistema do Universo, abandonamos essa obra de escandaloso delírio" (1920, p. 378). Verdade ou não, o certo é que, impulsionado pela introdução das operetas de Offenbach em Portugal, Eça chega a escrever o libreto de uma opereta ( $A$ morte do Diabo), com música de Augusto Machado 4 . Apesar da notícia de tal produção, até hoje tais documentos ainda não foram encontrados (Carvalho, 1999, p. 65).

Ora, se entendermos que a prática estética literária de Eça, num enfrentamento direto com a sociedade burguesa lisboeta, como afirmou Maria Lúcia Dal Farra, era composta essencialmente de "uma arte corrosiva e desmistificadora que pudesse se exercer por meio da caricatura, da ironia e do escárnio" (1995, p. 5), então, arriscamos uma via de leitura do romance eciano que passa necessariamente pelo viés da ironia, tomando como ponto de partida as referências musicais e operísticas, que, ao lado 
das leituras românticas efetuadas por Luíza, compõem o repertório ilusório da personagem com uma imaginação fadada a uma impossível concretização e a um fracasso irremediável.

Além de Walter Scott e de suas cenas de castelos na Escócia, de $A$ Dama das Camélias e da idealização paradisíaca de um Paul Féval, 0 primo Bazílioapresenta um elenco invejável de óperas e citações musicais dos mais variados gostos e escolas líricas, passando por Verdi ( $L a$ Traviatta), Donizetti (Lucia di Lamermoor), Bellini (Norma e La Sonâmbula), Rossini (/l Barbieri di Siviglia), Meyerbeer (L'Africaine), Gounod (Medjé, Romeu e Julieta e Fausto), Mozart (Missa di Réquieme Don Giovanni), incluindo ainda a peça para piano "Oração a uma virgem", um "Noturno" de Chopin, a valsa "O Danúbio azul" de Johann Strauss e a canção "Malagueña". Com todos estes exemplos tirados do século XIX, sob a égide de uma produção musical romântica, Eça parece perpetrar, através de um rico aparato cultural, o seu questionamento crítico à estética romântica, compondo assim uma espécie de requiem para o próprio Romantismo.

É, portanto, com a revisitação da tradição musical romântica, que Eça de Queirós compõe uma sinfonia crepuscular para um movimento em vias de declínio. É interessante observar que, com essa mesma tradição musical, o autor aponta, sobretudo em Os Maiase $A$ cidade e as serras, para um crepúsculo finissecular, um declínio epocal, que abre as portas para a Modernidade histórica e literária. Se muitos autores portugueses do século XX - como um Vergílio Ferreira e um Helder Macedo, por exemplo - utilizam o recurso do diálogo com outras expressões artísticas, como a música, evidenciando uma fronteira tênue entre os gêneros, háde se destacar que esta prática intertextual no reino da ficção, tem, talvez, em Eça de Queirós um marco sintomático e deflagrador.

De acordo com o pensamento dos críticos portugueses José Blanc de Portugal ${ }^{5}$ - um dos pioneiros a apontar os caminhos operísticos como um dos traços da modernidade em Eça de Queirós - e Mário Vieira de Carvalho ${ }^{6}$, a música é um leitmotiv pertinente para o estudo da ficção e do pensamento crítico de Eça de Queirós. Neste sentido, um olhar atento sobre $O$ Primo Bazílioe as suas ricas citações musicais torna-se necessário, até porque tais intertextos musicais reiteram aquela "estética da ironia" no romance eciano, como há muito já pontuara Mário Sacramento (1945).

Já nos primeiros capítulos, os compositores italianos são chamados ao palco do romance. A visão de mundo nublada pelas leituras românticas, aliada a um olhar cativante sobre Paris, com "as suas mobílias, as suas sentimentalidades" (Queirós, 1999, p. 18), aparece reiterada por uma educação sentimental bem ao gosto romântico. De um lado, o romance A Dama das Camélias, que tira de Luíza, ao término da leitura, "duas lágrimas a tremer-lhe nas pálpebras" (Queirós, 1999, p. 19), e de outro, a ópera La Traviatta, de Verdi, baseada na mesma obra de Alexandre Dumas, cuja ária final para soprano ("Addio, del passato") é cantada "baixinho, com ternura" (Queirós, 1999, p. 19) pela própria Luíza.

Mesmo sem indicar explicitamente o registro vocal da personagem, Eça dá uma sugestão ao leitor de que a personagem feminina não só se alimenta de leituras e referências culturais românticas, mas também as executa performaticamente, como se estivesse mesmo desempenhando o papel de uma prima donna do bel canto italiano, típico das sopranos intérpretes da época. E, por mais de uma vez, a voz de Luíza reitera este 
cenário, não apenas interpretando Verdi, mas também "com um olhar melancólico (...), sentando-se ao piano, ao anoitecer", quando "cantava Soares dos Passos: "Ai! adeus, acabaram-se os dias / Que ditoso vivi a teu lado..." (Queirós, 1999, p. 21); ou, ainda, com uma voz "fresca e clara", executando a "Mandolinata": "Amici, la notte é bella, / La luna va spontari.." (Queirós, 1999, p. 51).

Neste sentido, é bom lembrar que à época de escrita e publicação de O Primo Bazílio, a já referida ópera de Verdi havia estreado no Teatro São Carlos, em 1855, bem como as demais peças executadas languidamente por Luíza. A ópera de Bellini (La Sonambula) estréia em 1834 e a de Donizetti (Lucia di Lamermoor), quatro anos depois. Não seria, portanto, ingenuamente que Eça traria a cena algumas das principais peças dramático-musicais do século XIX, pelas mãos e pela voz de Luíza, logo depois da primeira visita de Basílio a sua casa, engendrando os planos de sedução e conquista:

Foi à sala, sentou-se ao piano, tocou ao acaso bocados da "Lucia", da "Sonâmbula", o "Fado"; e parando, os dedos pousados de leve sobre o teclado, pôs-se a pensar que Baźlio devia vir no dia seguinte: vestiria o roupão novo de foulard cor de castanho! Recomeçou o "Fado", mas os olhos cerravam-se-lhe. (Queirós, 1999, p. 71).

Já aqui, é possível vislumbrar um certo sentido irônico empregado pelo autor no diálogo intertextual com as peças musicais. Bem diferente de Violeta Valery (heroína de Verdi), que morre de maneira sublimadora, consumida pela tuberculose, acreditando piamente num amor regenerador; ou de Lucia di Lamermoor (heroína de Donizetti, recriada a partir do romance de Walter Scott), que termina consumada por um surto de loucura ao perceber que fora vítima de um plano algoz do irmão; ou, ainda, de Amina (protagonista da ópera de Bellini), acusada injustamente de traição, mas, ao final, perdoada diante da constatação de sua honestidade, Luíza guarda traços bem diferentes das personagens cujos papéis executa vocal ou pianisticamente.

Ao contrário de Amina, por exemplo, a traição de Luíza não ocorre num surto de sonambulismo, mas é executada com requintes de situações jamais sentidas anteriormente pela personagem e vivenciadas por ela no "Paraíso". Ela própria, bem diferente da protagonista de La Sonambula, já não tem forças ou vigor para entoar uma "típica ária de bravura da ópera italiana" (Harewood, 1994, p. 286), como é o caso de "Ah! non giunge". Nem mesmo Jorge aparenta-se a Elvino, capaz de colocar na esposa um anel de noivado e entoar alegremente, como o personagem de Bellini, "Viva Luíza".

Se na ópera de Donizetti, Lucia torna-se vítima do irmão e é induzida a impetrar um gesto de traição em relação ao seu amor por Edgardo, na "ópera" eciana, Luíza, a despeito de "viver num bom conforto, com um marido terno, uma casinha abrigada, colchões macios, uma noite de teatro, às vezes, e um bom almoço nas manhãs claras" (Queirós, 1999, p. 71), pensava na "idéia de uma outra existência mais poética, mais própria para os episódios do sentimento" (Ibidem), trazida pela presença de Bazílio. 
Não que, com isto, haja aqui a idéia de condenação sumária da personagem lisboeta, imputando sobre ela uma culpabilidade irretorquível. Na verdade, as melodias executadas das óperas trazem à tona a presença das suas heroínas que, apesar de participarem do ângulo de visão de mundo de Luíza, parecem bem destilar uma ironia do autor quando colocadas lado a lado com a postura e a trajetória desta. Basta lembrar que, em determinado momento, as mesmas referências musicais são apresentadas de forma irônica, bem diferente dos cenários italianizantes e requintados dos palcos teatrais, com um teor corrosivo e decadente:

Do outro lado do terreno, verduras de quintais, muros brancos davam àquele sítio um ar adormecido de vila pacata. Quase ninguém passava. Havia um silêncio fatigado; e só às vezes o som distante de um realejo, que tocava a "Norma" ou a "Lucia", punha uma melancolia na tarde. - E Juliana ali estava imóvel, até que os sons quentes da tarde empalideciam, e os morcegos começavam a voar. (Queirós, 1999, p. 89; grifos meus).

Além das óperas italianas, há-de se pontuar duas óperas francesas oitocentistas de Charles Gounod, Fausto e Romeu e Julieta. A primeira traz a emblemática figura de Mefistófeles, personagem que, segundo o próprio Eça, tem "uma vida real e poderosa" (Queirós, 1999b, p. 249), "tem o escárnio, tem a violência, tem as trevas, a jovialidade e o medo. Range, ri, treme, devasta, insulta e vence" (Queirós, 1999b, p. 251). Interpretada pela voz de Bazílio, ao "cantarolar a ária do terceiro ato do Fausto: Al pallido chiarore / Dei astri d'oro..." (Queirós, 1999, p. 174), a cena desvela já o olhar irônico com que Eça lança sobre o "episódio familiar" e ainda faz ressoar a gargalhada de seu Mefistófeles. O mesmo Fausto é apresentado no capítulo XIII, quando Luíza, Jorge e D. Felicidade dirigem-se ao Teatro São Carlos para o espetáculo. Num jogo de espelhos, Luíza parece ver na encenação operística o seu próprio drama, não só pela lembrança repentina de ver-se "sentada no divã, na sua sala, ainda tomada dos soluços de adultério" (Queirós, 1999, p. 388), mas também por, de certa forma, presenciar a impossibilidade daquilo que constatara no "Paraíso", quando do seu diálogo com Bazílio. Ao contrário daquela "sensualidade delicada e moderna, com elances de um requinte devoto" (Queirós, 1999, p. 388), característica do "modo expirante" (Queirós, 1999, p. 388) do dueto de Fausto e Margarida, Bazílio deixa sua máscara cair ao advertir Luíza que eles jamais poderiam encenar "Laisse-moi contempler ton visage" ou "O nuit d'amour.. ciel radieux!" (os famosos duetos dos protagonistas de Gounod): "- Mas sê razoável, minha querida. Uma ligação como a nossa não é o dueto do Fausto. Eu amo-te; tu, creio, gostas de mim; fazemos os sacrifícios necessários, encontramo-nos, somos felizes... Que diabo queres tu mais? Porque te queixas?" (Queirós, 1999, p. 223). Se por um lado, a performance de Bazílio mais se aproxima de Mefistófeles do que de Fausto, é bom lembrar que os dois jamais realmente poderiam executar tal dueto, já que o papel do protagonista da ópera está destinado a um tenor, portanto, Bazílio, com a sua voz "cheia, bem timbrada, de barítono" (Queirós, 1999, p. 108) só poderia interpretar 
Mefistófeles ou, quem sabe, um Don Giovanni, o que também, aliás, incorreria em outro desempenho irônico, porque, se na ópera de Mozart, o dissoluto é punido, na ópera eciana, ele termina andando tranqüilamente pelas ruas de Lisboa, sem estátuas de Comendador ou coros infernais a condená-lo.

Talvez, diante desta impossibilidade performática, a outra ópera de Gounod, Romeu e Julieta, um dos ícones do drama musical romântico, apareça sem chance de execução, na imagem decepcionada de Sebastião com o "grosso volume debaixo do braço" (Queirós, 1999, p. 115) da partitura e que Luiza "desejava tanto ouvir" (Queirós, 1999, p. 114). Mas, em contrapartida, se esta "ópera lírica"7 não é ouvida nem por Luiza e nem pelos leitores do romance eciano, outro gênero musical francês se destaca ao longo da trama de O Primo Bazílio. a opereta. Considerada uma espécie de continuação da ópera bufa (ou cômica) ${ }^{8}$, a opereta demarca o seu espaço nos palcos teatrais pelo mais puro vigor do seu estilo parodístico, irônico e irreverente em relação aos grandes dramas líricos e ao próprio sistema burguês que alimentou o amadurecimento e propagação destas composições. ${ }^{99}$

Segundo Mário Vieira de Carvalho (1999, p. 65-66), as datas de 1868 e 1869 são emblemáticas no cenário cultural português, posto que marcam a estréia das operetas de Offenbach, sobretudo La GrandDuchese de Gérolstein, no Teatro Príncipe Real, causando um forte impacto em Eça de Queirós, a ponto de distanciá-lo de um certo tom romântico, até então alimentado em sua produção literária, comprovado em alguns textos de Prosas Bárbaras.

No romance, é, primeiramente, Leopoldina, que, num tom frívolo e irreverente, executa, com "a sua voz mordente, a sua canção querida da Grã-Duquesa. Ouvi dizer que meu avô de vinho / Era um tal amador...", sob o olhar reticente de Luíza, que achava "aquela música 'espalhafatona'; queria alguma coisa triste, doce..." (Queirós, 1999, p. 162). Contrapondo duas visões de mundo tão diferentes, Eça constrói nesta cena uma espécie de palco operístico, onde duas prima donnas expõem os seus anseios a partir de árias e canções que preenchem as suas perspectivas. De um lado, a melodia espalhafatosa de Leopoldina, sugerindo a performance de uma soprano ligeiro, por exemplo, e de outro o tema lânguido de Luíza, reiterando o seu timbre lírico também de soprano, reiterados pelas ambições e desejos das personagens:

Luíza não ambicionava um coupé, e queria viajar, ir a Paris, a Sevilha, a Roma... Mas os desejos de Leopoldina eram mais vastos: invejava uma larga vida, com carruagens, camarotes de assinatura, uma casa em Sintra, ceias, bailes, toilettes, jogo... Porque gostava do monte - dizia - fazia-lhe bater o coração. E estava convencida que havia de adorar a roleta. (Queirós, 1999, p. 167).

Ora, como não atentar, aqui, para aquela crítica ao sistema ideológico burguês que a opereta desencadeava ao longo de suas tramas? Como não pontuar o olhar crítico de Eça, utilizando-se de um gênero que começava a varrer o cenário cultural português? Não seria gratuito, neste 
sentido, o fato de a mesma opereta reaparecer no romance, agora, revestida de uma roupagem caricatural, não mais na voz de Leopoldina, mas na de Juliana, que de forma "despretensiosa", cantarolava a ária "A Carta Adorada", no exato instante em que Luzia escrevia sua carta a Bazílio. Em outro momento, Eça cria um outro cenário bem típico daquele tom irreverente com que as operetas parodiavam e zombavam das grandes melodias românticas, ao colocar Juliana, atirando "vassouradas rápidas", com um "júbilo agudo", "soltando na sua voz rachada: Além d'amanhã termina a campanha, /P-o-o-or aqui se diz... / Se tal for verdade, se não for patranha... E com um espírito enfático: Se-e-rei bem feliz!' Queirós, 1999, p. 192).

Cena marcante do romance, segundo Mário Vieira de Carvalho, a introdução de Offenbach no elenco musical de O Primo Bazíliotem uma dupla função representativa: de um lado demarca "a rebelião potencial de Juliana", em pleno processo de ávida desforra, e de outro deflagra a "vaga percepção de Luíza da ameaça que representava o ódio da classe servil" (1999, p. 39).

Ora, se realmente "é iniludível, em toda a obra de Eça, a existência de um impulso tendente à construção teatral" (Sacramento, 1945, p. 169), como nos faz crer Mário Sacramento, então, valendo-se de intertextos musicais, gosto de pensar na possibilidade de que Eça de Queirós procura em $O$ Primo Bazílio deslindar todo aquele seu projeto de construção de uma ópera bufa (ou, quem sabe, de uma opereta mesmo), mas não no sentido de que o romance possa ser considerado exclusivamente como tal. O projeto operístico parece estar ali, mas com as citações musicais e as suas retomadas irônicas, parodiando trechos líricos e colocando-os num sentido outro, de cariz performática corrosiva e abertamente decadente.

Neste sentido, a voz de Jorge, cantarolando "com um tom fúnebre" (Queirós, 1999, p. 346), o "Dies irae", do Requiem de Mozart (Dies irae, dies illa, / Solvet saeculum in favilla!...), depois do pedido de Luíza, em seus instantes finais de vida, a Sebastião, parece ter uma função mais ampla que a de mera citação. Longe da figura que exalava sedução e beleza e destilava anseios românticos e idílicos, Luíza aparece derradeiramente corroída, com as suas "lindas tranças, destruídas às tesouradas" (Queirós, 1999, p. 432), e a sua pele empalidecida "como um vidro de janela por trás do qual lentamente uma luz se apaga" (Queirós, 1999, p. 433).

Do apogeu da sedução à derrocada da morte, seguida da irônica declamação dos versos de Garrett, nem na morte, a visão de mundo romântica parece abandonar a personagem. Daí que o "Dies irae", executado pela voz de baixo de Jorge, possa ser entendido não apenas como uma prece antecipada à figura de Luíza, mas também como um canto fúnebre aos valores defasados e à mundividência embotada que a personagem encarnava. Interessante observar que este irônico requiem entoado ao modus vivendiromântico ganha uma última gargalhada, se não a de Mefistófeles, talvez, a de um Don Giovanni, acompanhado de seu Leporello. Caminhando ambos pelas ruas de Lisboa, após receberem a notícia do falecimento de Luíza, Bazílio e Reinaldo representam assim esta última cena, quando os dois, antes de irem "tomar xerez à Taverna Inglesa", "riram-se muito de um sujeito que passava governando atarantadamente dois cavalos pretos" (Queirós, 1999, p. 451; grifo meu). 
Parece que, por estas figuras performáticas, Eça põe em prática aquele jogo com "a variedade dos timbres" (D'Almeida, 1993, p. 80), em que a disposição dos diferentes tipos vocais (sopranos, barítonos e baixos, propositalmente sem a presença de um típico tenor protagonista) indica a sua sugestão de que a Música seria, talvez, o veículo adequado para expressão dessa mocidade lisboeta triste, enervada e descompassada de seu contexto europeu. Neste sentido, O Primo Bazílio pode ser entendido como uma grande investida nos rumos de uma Modernidade necessária, pelo menos, nos caminhos da construção ficcional. E não seria este mesmo o projeto eciano? O que faz ele no romance se não "o quadro do mundo moderno, nas feições em que ele é mau, por persistir em se educar segundo o passado"? Ou ainda, a "caricatura do velho mundo burguês, sentimental, devoto, católico, explorador, aristocrático, etc. $E$ apontando-o ao escárnio, à gargalhada, ao desprezo do mundo moderno e democrático - preparar a sua ruína"? (Queirós, s.d., p. 45).

Mais de 130 anos depois, O Primo Bazílio ainda guarda o frescor de seu projeto inicial, qual seja, o de um "episódio doméstico" que intenta devassar as paredes dos cenários e dos teatros lisboetas e se tornar naquele "auxiliar poderoso da ciência revolucionária" (Queirós, s.d., p. 45), oferecendo ao seu leitor a possibilidade de vislumbrar um espetáculo onde a ironia ressoa em plena consonância com a gargalhada de Mefistófeles que, se bem pode ser confundida com a de um Don Giovanni, também pode suscitar zombeteiramente os ecos da ária do Duque de Mântua, personagem da ópera Rigoletto, de Giuseppe Verdi, afinal, "La donna è mobile qual piùma al vento / Muta d'accento e di pensier" (Adler, 1954, p. 210).

Assim, pelas possíveis árias e cavatinas, performatizadas ficcionalmente pelos seus sopranos e barítonos, Eça parece revisitar a ópera oitocentista, criando o seu elenco e o seu próprio libreto, deixando passar, enfim, pelas linhas melódicas da ironia, o seu último suspiro, o seu requiem a um romantismo que não podia mais dar conta da perspectiva de mundo pretendida.

Se, realmente, na música, "nada nasce do nada" (D'Almeida, 1993, p. 120), como bem nos ensina António Vitorino D'Almeida, então, somos tentados a pensar que, sobretudo no romance $O$ Primo Bazílio, nenhuma das citações empregadas por Eça de Queirós são gratuitas ou nascem sem um propósito definido e eficaz. "Tal como as cores, os sons são generosos" (D'Almeida, 1993, p. 120), basta, portanto, aos leitores usufruírem desta generosidade feita em forma de música, de ópera e, enfim, de ficção.

\section{REFERÊNCIAS BIBLIOGRÁFICAS}

ADLER, Kurt (comp.) Operatic Anthology. Celebrated Arias Selected from Operas by Old and Modern Composers. New York: Schirmer, Inc., 1954. CARVALHO, Mário Vieira de. A cultura músico-teatral na crónica e na ficção queirosianas: pistas para a definição de um perfil estético. Camões. Revista de Letras e Culturas Lusófonas. Lisboa: Instituto Camões, abril-setembro, p. 114-126, 2000.

. Eça de Queirós e Offenbach. A ácida gargalhada de Mefistófeles. Lisboa: Colibri, 1999. 
CARVALHO, Mário Vieira de. Pensar é Morrer ou O Teatro de São Carlos na mudança de sistemas sociocomunicativos desde fins do séc. XVIII aos nossos dias. Lisboa: Imprensa Nacional - Casa da Moeda, 1993.

COELHO, Lauro Machado. A Ópera na França. São Paulo: Perspectiva, 1999.

DAL FARRA, Maria Lúcia. Eça educador e aprendiz. In: QUEIRÓS, Eça de. O Primo Basílio. São Paulo: Ática, 1995, p. 3-10.

D'ALMEIDA, António Vitorino. O que é Música. Lisboa: Difusão Cultural, 1993.

GROUT, Donald J. \& PALISCA, Claude V. História da Música Ocidental. .: Ana Luisa Faria. 2a ${ }^{a}$. ed. Lisboa: Gradiva, 2001.

HAREWOOD, Conde de (ed.). Kobbé. O Livro Completo da Ópera. Trad.: Clóvis Marques. Rio de Janeiro: Jorge Zahar, 1994.

HAUSER, Arnold. História Social da Literatura e da Arte. Trad.: Walter H. Geenen. $3^{a}$. ed. São Paulo: Mestre Jou, 1982, vol. II.

PORTUGAL, José Blanc de. Relance sobre a música no século XIX português, com ocasionais referências à música em Os Maias de Eça de Queirós. Atlântico. Revista Luso-Brasileira. Lisboa, nova série, no. 3, p. 62-69, 1947.

QUEIRÓS, Eça de. Cartas e outros escritos. Lisboa: Edições "Livros do Brasil", [s.d.].

Brasiliense, 1961.

Cartas Inéditas de Fradique Mendes. São Paulo: . Notas Contemporâneas. $3^{a}$. ed. Porto: Livraria Chardron,

1920.

. O Primo Bazílio. Lisboa: Edições "Livros do Brasil", 1999. . Os Maias. São Paulo: Ateliê Editorial, 2003.

1999b.

Prosas Bárbaras. Lisboa: Edições "Livros do Brasil",

SACRAMENTO, Mário. Eça de Queirós: uma estética da ironia. Coimbra:

Coimbra Editora, 1945.

\section{NOTAS}

1. Em sua História Social da Literatura e da Arte, Arnold Hauser chama a atenção sobre o impacto que o gênero romanesco causou na Europa Oitocentista, principalmente o romance de folhetim que, segundo ele, foi um caso "sem precedentes na literatura. (...) Nunca uma arte foi aceite com tanta unanimidade por camadas sociais tão diferentes, e recebida com sentimentos tão semelhantes." (1982, p. 896). Já sobre a ópera, Grout \& Paliska sublinham a presença de uma "classe média numerosa e cada vez mais influente a partir de 1820" como fator catalisador do surgimento de um novo gênero operístico: a grande ópera. (2000, p. 628-629).

2. Entendemos, aqui, o Portugal cênico do século XIX como aquele que envolve basicamente o Teatro Nacional D. Maria II (inaugurado em 1846) e o Teatro São Carlos (fundado em 1793).

3. Em virtude da edição utilizada para o presente trabalho (Livros do Brasil), respeitaremos a grafia do título da obra apresentada.

4. Augusto Machado (1845-1924), compositor, maestro e pianista português, suas obras sofreram influências diretas dos mestres franceses Camile Saint-Sãens e Jules Massenet, sobretudo em suas óperas. Além de Diretor do Teatro São Carlos, foi professor do Conservatório Nacional. Contemporâneo dos intelectuais da Geração de 70, fez parte também do Cenáculo, tertúlia literária que ainda contava com as presenças de Jaime Batalha Reis, Eça de Queirós, Antero de Quental e Guerra Junqueiro, dentre outros. As suas performances inspirariam Eça na composição do personagem 
Cruges, de Os Maias, pintado como "um diabo adoidado, maestro, pianista, com uma pontinha de gênio" (Queirós, 2003, p. 74).

5. Retomo, aqui, apenas a título de citação, um dos primeiros estudos sobre a presença da música na obra de Eça de Queirós (Portugal, 1947, p. 62-69).

6. Atualmente, é um dos principais críticos e, arrisco-me a afirmar, uma das mais autenticadas autoridades sobre os estudos culturais e musicais na obra eciana (Carvalho, 1999 e 2000).

7. Consideramos, aqui, a definição do termo, de acordo com Lauro Machado Coelho. Segundo ele, "entre a pompa do Grand-Opéra e a vivacidade mais descomprometida do opéra-comique de assunto sentimental, havia espaço para que se desenvolvesse um tipo de ópera que fosse menos solene e pretensioso do que o primeiro, mas tivesse um grau de elaboração musical e de seriedade maior que o segundo. Esse gênero será o opéra-lyrique, que oscila entre o uso do recitativo a companhado e do diálogo falado. Mas recorre a meios de expressão mais contidos e tem dimensões menores do que os superespetáculos meyerbeerianos. Oferece, porém, uma concentração emocional e um refinamento de escrita a qual não visavam os colaboradores do Théâtre de l'Opéra-Comique. Na geração anterior a 1870, os dois principais representantes dessa tendência serão Ambroise Thomas e Charles Gounod." (1999, p. 169).

8. Amplamente explorada e consolidada nos palcos italianos setecentistas, a ópera bufa ou ópera cômica diferenciam-se dos dramas sérios pelos temas encenados nos seus libretos. São obras que, "em vez de abordarem temas heróicos ou mitológicos, apresentam episódios e personagens familiares, podendo ser levadas à cena com recursos relativamente modestos." (Grout \& Palisca, 2001, p. 501). Sua importância foi fundamental para a defesa de determinados idéias estéticos do romantismo, visto que seus libretos eram, quase de maneira geral, produzidos nas diferentes línguas nacionais de seus compositores. Com isto, afirmam Grout e Palisca que "sua relevância histórica foi dupla: por um lado, respondeu à exigência universal de naturalidade da segunda metade do século XVIII e, por outro, foi o primeiro grande veículo do movimento no sentido do nacionalismo musical, que viria a afirmarse no período romântico." (2001, p. 501).

9. Sobre o gênero em questão e o seu impacto no meio social e intelectual, Hauser pontua que: "a opereta desmoralizava o público, não por zombar de tudo que era 'venerável', não por ridularizar a Antigüidade, a tragédia clássica, a ópera romântica, cujo significado era apenas uma crítica disfarçada à sociedade, mas por aniquilar a crença na autoridade sem no princípio nega-la. A dubiedade da opereta consistia na despreocupada tolerância com que conduzia a sua crítica ao corrupto sistema de governo e da depravada sociedade da época, na aparência da inofensividade que atribuía à frivolidade das prostitutazinhas, aos galanteadores ruinosos e aos velhos viveurs amáveis. A sua crítica tépida, hesitante, não fazia senão estimular a corrupção" (1982, p. 979-980). 